\title{
A REVIEW PAPER ON: ANALYSIS OF ON- GROUND RECTANGULAR TANK FOR COMPUTING SHEAR AND MOMENT COEFFICIENTS
}

\author{
Shriniwas M. Patki \\ Department of Civil Engineering \\ K.D.K. College of Engineering \\ Nagpur, Maharashtra, India
}

\author{
Dr. H D Chandewar \\ Structural Consultant \\ Hitbhav Engineers \\ Nagpur, Maharashtra
}

\author{
Dr. N. R. Dhamge \\ Department of Civil Engineering \\ K.D.K. College of Engineering \\ Nagpur, Maharashtra, India
}

\begin{abstract}
Rectangular water tanks are difficult and tedious to analyse therefore various methods especially FEM are made for finding the solution to problems which occur during analysis. Since the rectangular tank uses complete space and are cost effective, therefore these are being mostly used in industrial region, WTPs, STPs, etc. Various codes and books are available for design of rectangular water tank which gives coefficient for moments for designing of tanks such as IS Code, Moody's chart, Reynolds handbook, etc. This paper reviews the literature on finding moment coefficients for rectangular water tank which helps to perform new technique to check the coefficient, if have any correction for further analysis and also presents general method such as analytical method, FEM, approximate method for analysis of water tanks and continuous plate structures.
\end{abstract}

Keywords- Ground support rectangular water tank, moment coefficient, rectangular plates, deflection in rectangular plates, Staad pro or SAP.

\section{INTRODUCTION}

Water is human basic needs for daily life. Sufficient water distribution depends on design of a water tank in certain area. There are mainly two types of tanks: ground supported tanks and elevated tanks. Ground-supported tanks are generally of reinforced concrete, pre-stressed concrete, or steel. Rectangular water tank are used when the storage capacity is small and the area for storage of water is very small. These types of tank are difficult to analyse and therefore when these tanks are analysed we analyse for each panel i.e. individual wall panel or wall sides (long and short wall) are analysed and then combined to form a tank.

Continuous plates occur in a wide range of structures, and a number of methods are available for the static analysis of the structural systems. By considering thin plate theory, exact analysis is only possible when two opposite edges are simply supported but with other boundary conditions numerical solutions are required. Tanks represent a class of continuous plate structures which have been the subject of extensive investigations.

Generally square tank are analysed or considered in which vertical junctions are assumed that they do not rotate and hence each panels can be analysed as plates fixed on two vertical edges, and with a variety of boundary conditions on the two horizontal edges. When rectangular wall panels are considered which contain multiple cells and rotations of vertical junctions in general occur then such structures may be treated using finite element method or approximation technique. In using finite elements or finite differences a large number of equations require solution.

In most of the design tables it is observed that, generally moment coefficients are specified assuming fixity along base slab and the two vertical joints. I.S. code 3370 (Part IV) provides moment coefficients for plate subjected to hydrostatic loading with idealized boundary conditions that, fixity along two vertical edges as well as the base (i.e. the bottom edge) and free at the top edge. However due to monolithic connection between the base slab and walls, rotation of edges do occur which significantly changes the moment coefficients given in I.S Codes. But in the case of rectangular tanks, the vertical edges of the wall will also undergo rotation. I.S. code does not take into account the effect of axial forces and the rotation of edges. Therefore B.M. Values obtained by using I.S. code values are required to be modified depending upon the relative stiffness. Finite Element Method is powerful mathematical tool to solve engineering problems.

This method is preferred for analysis because of the following reasons:

1. F.E.M. permits the full interaction between the walls, floor and roof of the tank and changes in aspect ratios or sizes and the thickness of members to easily to be considered in the general program. 
2. The ease with which the boundary conditions can be applied.

3. It is possible to determine the internal forces at number of points, so as to plot its variation along any given direction.

\section{REASEARCH FINDING}

The detailed studies of ground rectangular water tank using softerware will be investigated based on various literature papers.

1) B. W. Golley and j. F'etrolito (1984) discuss in this paper about a continuous plate and square tank which is considered for bending moment analysis. For each panel two different type of load varying linearly in two direction is considered which are uniform load and hydrostatic load by which analysis is done. In this paper stiffness method is used for analysis of moments considering each span as single element. In this paper two examples are taken to compare the exact solution with the existing tables. In first example a square tank is considered with internal hydrostatic pressure varying from 0 to $p$ with top edges free and bottom and side edges fixed. In second example a continuous plate is considered by considering boundary conditions with uniformly loaded condition for analysis. In both examples poisons ratio is considered as 0.2 . From the above examples it was found that in square tank the moments with existing table and the moments from the exact solution almost match with each other. The moments from the exact analysis have higher accuracy.

2) Mr.Akshay R. Desale, et.al(2018) discuss in this paper about an elevated rectangular tank which is considered with monolithic connection between long wall and short wall and base slab. An elevated rectangular tank is analysed by finite element method i.e by Ansys software which based on FEM. Various dimensions are considered for the analysis of the tank and each wall is discredited into 4 noded element with six degree of freedom. The type of loading is hydrostatic load with poisons ratio 0.2 . From the above analysis it was seen that moments given by IS 3370 are exactly opposite in nature as compared to moments found in analysis for partially filled condition. At the same location in wall the moments proposed by IS Code do not match with the moments given by FEM.

3) Morris, Jordan MSCE, et.al (2014) - In this paper coefficients are identified by using fem and are modified in PCA table for rectangular plates. In this the long wall and short wall are designed by FEM in software's such as Staad Pro, SAP, Ansys. Specially, SAP is used for the purpose of analysis as it was giving more accurate results than the other software's. In this walls are designed by using various support condition and loading condition. From the observation from the tables given in the table it was found that SAP gives more similar results when compare to PCA tables thus the PCA tables could be used for designing of rectangular water tank. It gives more accurate results and wider database for the analysis of water tank thus giving critical location for the failure of wall. Also the \% error is permissible i.e $1.31 \%$ as maximum \%error making it useful for the analysis of water tank.

4) Issar Kapadia, Purav Patel, et.al(2017) - In this paper underground rectangular water tank is designed for empty condition in Staad Pro software. The tank is designed for various dimension and support condition. From the above analysis it was found that rectangular tank are used for small capacities as it was very cost effective. The longer side of the wall should be less than twice the smaller side. Also the moments are higher at support and at mid-base.

5) W T Moody (1963) - This reference book gives the idea of analysis of rectangular plates. To determine the coefficients various assumptions are made such as hook's law, and relative magnitudes of deflections, thickness, and lateral dimensions. In this various cases were considered for analysis of tank such as boundary condition and loading condition to obtain the desired result. All the numerical values are based on poisons ratio of 0.2 . This book gives the different coefficient for the poisson ratio of 0.2 which helps in designing the rectangular water tank. From this it was concluded that the coefficient by FEM and by Timoshenko are almost similar with minute error.

6) Jofriet(1984) found out several tables of moment coefficients by exact analysis when he determined the influence of uniform wall thickness on vertical bending moments and on horizontal edge moments in walls of length/height ratios greater than three. His solutions, however, only included conventional boundary conditions.

7) Davies and Cheung determine coefficients for moment for tank by using finite element method assuming that the wall-to-wall joints were clamped, the top edges were both free and simple supported and the bottom edges were simply supported or clamped. If the tank was open at the top, Davies determined his bending moments directly from statics, that is, the wall acted like a cantilever, which does not reflect the continuity of the wall.

\section{CONCLUSION}

\section{From the above literature survey it is found that:}

1. By using FEM, in case of square tank the moments match with the exact solution but in case of rectangular tank moments have $3 \%$ to $4 \%$ error.

2. With same poisons ratio of 0.2 , the moments by FEM and from IS Code method do not match with each other. 
3. According to the analysis from the above paper it is conclude that the moments from FEM are more accurate than calculated manually.

4. No coefficients are available in IS Code-3370(part-4) for complete water tank which have condition like fixed at base, fixed at side edges and free at top.

5. Since the coefficients for moment of rectangular plate are available for critical section therefore more coefficients can be find out for complete rectangular plate or complete rectangular tank so that reinforcement get reduces thus decreasing the cost of project.

6. Coefficients are available for individual wall panels with different end conditions in IS Code.

7. Coefficients can derive with the help new software's which uses FEM such as SAP, Staad Pro, Ansys, etc.

\section{ACKNOWLEGMENT}

I would like to express my special thanks to my guide Prof. Dr. N. R. Dhamge, who helps me to choose this wonderful project and also provided me lots of information about topic which helped to do research work more efficiently. Lastly I wish to thank Er. H D Chandewar Sir, for providing me knowledge about various methods applying for design of ground rectangular water tank and finalising the topic for project.

\section{REFERENCE}

[1] Golley B W And Fetrolit J (1983) "method for analysing tanks and continuous plates, Elsevier, Vol.18pp. 11411151

[2] Morris, et.al (2014) "Expansion of pca rectangular concrete tank plate tables", American society of civil engineer(ASCE), pp 1563-1573.

[3] Mr.Desale Akshay, Dr.Rathi V R (2018) "Parametric study of rectangular water tank for various loading conditions and edge rotation effect using finite element method", International Journal of Scientific Development and Research (IJSDR), Volume 3, Issue 9ISSN: pp 24552631

[4] Kapadia Issar, Patel Nikunj et.al (2017) “ Analysis of R.C.C. Rectangular Water Tank Resting on Ground as per IS Codes Provision by STAAD Pro Software "IJSRD, ,2109-2135

[5] IS : 3370 (Part IV)- 1967, Code of Practice Bureau of Indian Standard for Concrete Structures for Storage of Liquids, Design Tables

[6] Punmia B C, Jain Ashok (2015), “Textbook of Reinforced concrete design", $10^{\mathrm{TH}}$ EDITION, Laxmi publication, Chapter 21\&23, pp 589-697.

[7] Chau $K W$ And Lee $S T$ (1990), computer-aided design package rectangular tank for the analysis and design of reinforced concrete tanks, Elsevier, Vol. 41. No. 4, pp. 789-799.

[8] Moslemi M, Kianoush M R (2012),"parametric study on dynamic behaviour of cylindrical ground-supported tanks", Elsevier, 25 April 2012, pp 214-230.

[9] Abba Masud Alfanda, Abdulwarith Ibrahim Farouk (2017), "comparative analysis of circular and rectangular reinforced concrete tanks based on economical design perspective", ASCE,pp 214-224

[10] Chavhan Payal, Dorle Sneha, et.al.(2019) "Case study on water tank resting on ground" International Journal of Research in Engineering, Science and Management Volume-2, Issue-3, IJIRSET (Online):pp 2581-5792

[11] IS : 3370 (Part II)- 2009, Code of Practice Bureau of Indian Standards for Concrete Structures for Storage of Liquids

[12] Badipatla Balaji Sai, rao Virabhadra (2007), "parametric study of water retaining rc structures on ground and below ground subjected to hydrodynamic forces", GVP College of Engineering(A), Madhurawada, Visakhaptnam, International journal of innovation research in science and technology(IJIRSET)

[13] Kumara Deepak, et.al (2016) "Comparative Study of Dynamic Analysis of Rectangular Liquid Filled Containers Using Codal Provisions”, Elsevier, pp 14141430 